\title{
Examining the relationships between NCLEX-RN performance and nursing student factors, including undergraduate nursing program performance: $A$ systematic review
}

\author{
Nancy A. Sears ${ }^{* 1}$, Maha Othman ${ }^{1}$, Kelsie Mahoney ${ }^{2}$ \\ ${ }^{1}$ School of Baccalaureate Nursing, St. Lawrence College, Kingston, Ontario, Canada \\ ${ }^{2}$ School of Community Services, St. Lawrence College, Kingston, Ontario, Canada
}

Received: July 8, 2015

DOI: $10.5430 /$ jnep.v5n $11 \mathrm{p} 10$
Accepted: July 28, 2015

URL: http://dx.doi.org/10.5430/jnep.v5n11p10

\begin{abstract}
The National Council Licensure Examination for Registered Nursing (NCLEX-RN) replaced the Canadian Registered Nursing Examination (CRNE) in January 2015 as part of the requirements for qualifying for registered nurse (RN) status in all but one Canadian province. This substantial change is likely to have a profound impact on Canadian undergraduate nursing degree programs practices. This systematic review aims to examine the evidence describing the relationship between undergraduate nursing program performance and NCLEX-RN performance by registered nursing candidates as well as other factors contributing to NCLEX-RN success. An initial search of CINAHL and Medline databases using key terms NCLEX and predict, publication dates between 1984-2015 revealed 46 articles of interest. 28 articles were examined for eligibility and 17 articles with clear evidence and descriptions were included. Thematic groupings of academic, cognitive, individual factors and models for successes are presented. The review showed academic factors are strong predictors for NCLEX-RN success. Cognitive factors, particularly critical thinking skills, are correlated with NCLEX-RN success. Stress and highly negative emotions inversely correlate with NCLEX-RN success. Speaking English as a first language showed high correlation with NCLEX success, while other nonacademic factors such as age, gender and ethnicity showed varying results. All these factors have implications for nursing programs' practices and students. Research studies need to begin immediately, not only to define and predict factors for NCLEXRN success within its new Canadian arena, but also to evaluate the outcomes of this exam at baseline and frequent intervals within this population. This will enhance nursing programs' support of students' success.
\end{abstract}

Key Words: National Council Licensure Examination (NCLEX), Nursing program, Nursing degree, Performance factors, Health Education Service Incorporated (HESI)

\section{INTRODUCTION}

Graduates of nursing degree programs across Canada must successfully complete standardized nursing registration examinations to qualify for designation as a registered nurse by their professional regulatory body. It follows that undergraduate degree programs have a vested interest in ensuring that their graduating students have been well prepared for these exams. The extent to which graduates of nursing programs

\footnotetext{
*Correspondence: Nancy A. Sears; Email: nsears@ @l.on.ca; Address: School of Baccalaureate Nursing, St. Lawrence College, Kingston, Ontario, Canada.
} 
successfully perform on standardized nursing registration examinations can have a profound impact on the prestige of nursing programs and as such serve as a recruitment factor for these programs. ${ }^{[1]}$ With the National Council Licensure Examination for Registered Nursing (NCLEX-RN) replacing the Canadian Registered Nursing Examination (CRNE) in January 2015, knowing the factors that influence students' abilities to pass this new examination can aid programs' adjustments for this change. Many factors have been examined for their influence on NCLEX-RN pass rates of American students. While many studies are qualitative in nature, there are some quantitative analyses that identify factors that have a significant influence on students' ability to pass. ${ }^{[1]}$ This systematic review aims to dissect these factors, dividing them into three categories: academic factors, cognitive factors and individual factors.

\section{LITERATURE SEARCH}

This systematic literature review was designed to identify and synthesize all high quality research evidence relevant to the question of what is known about the relationship between undergraduate nursing program performance and NCLEX$\mathrm{RN}$ performance by registered nursing candidates that have recently graduated from nursing programs and what other factors may be known for NCLEX-RN success. A search of CINAHL and Medline databases using key terms NCLEX and predict, and limitations of peer-review, full text availability and publication dates between 1984 and 2015 inclusive was used to locate articles of interest. CINHAL yielded 21 articles under these conditions, while Medline yielded 68 articles. After duplications were removed from the searches, 46 articles remained. These records were screened and any articles regarding the practical nursing examination, and other professional examinations or assessment tests were removed. Articles debating different examinations or studying very small student populations were also removed. This resulted in 28 articles for assessment of eligibility. Eleven articles were removed due lack of clear evidence or descriptions of procedures or measures. After these articles were removed, 17 articles were included in the synthesis. The results of an analysis of the 17 articles is provided under the thematic groupings of academic factors, cognitive factors, individual factors and models for success (see Figure 1). An additional seven articles were included to provide qualitative evidence in support of the discussion and interpretation of the review results.

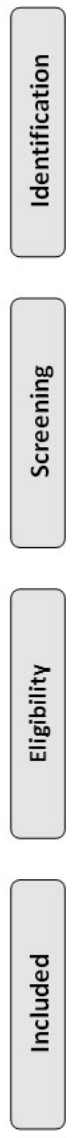

Additional records identified through other sources $(n=0)$

$$
(n=89)
$$

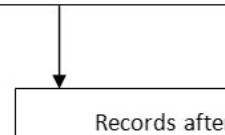

Records after duplicates removed

$(n=46)$

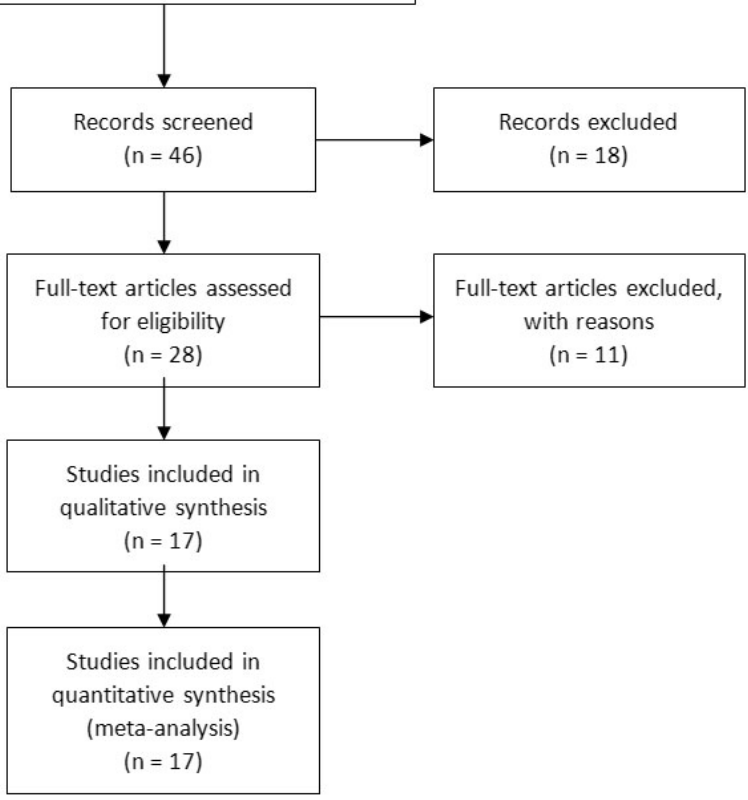

Figure 1. Literature search flow diagram 


\subsection{Academic factors}

Academic factors are often highly correlated with success on the NCLEX-RN and some are implicated even prior to entrance to a nursing program. Correlational studies with Scholastic Aptitude Test (SAT) scores provide contradictory evidence with Romeo ${ }^{[2]}$ finding little significance and Haas, Nugent, and Rule ${ }^{[3]}$ finding a significant relationship between SAT verbal and quantitative scores and NCLEX-RN scores. Grade point averages (GPAs) when entering nursing programs have been examined for predictive ability in passing the NCLEX-RN. Bosch, Doshier, and Gess-Newsome ${ }^{[4]}$ found entry GPAs to be highly significant for predicting success on the NCLEX-RN and the most significant contributor for a model that was successful at predicting failure on the exam $70.6 \%$ of the time. While chemistry and biology GPAs are sometimes segregated from an overall GPA for predicting success, ${ }^{[5]}$ several studies found overall entrance GPA is a significant factor in success prediction. ${ }^{[6,7]}$ However, Uyehara, Magnussen, Itano, and Zhang ${ }^{[8]}$ found both entrance and nursing GPAs not to be significant factors in predicting NCLEX-RN success. This is in contrast with a preponderance of findings that higher nursing GPAs are highly correlated with NCLEX-RN success. ${ }^{[5,7,9-12]}$ Consistent with this, Romeo ${ }^{[2]}$ found nursing GPAs to be the most significant predictor for NCLEX-RN success, while Giddens \& Gloeckner ${ }^{[13]}$ found program GPSs have a large effect size $(p \leq .001)$ on NCLEX-RN performance. Haas, Nugent and Rule $^{[3]}$ found nursing GPAs to be significant in prediction to the point that those that were successful on the NCLEX$\mathrm{RN}$ had nursing program GPAs that were 0.3 points higher than those that failed, however the GPA point score at which this difference occurred was not provided. Despite some contradictory studies, entry to program and program GPAs appear to be significant factors in prediction for NCLEX-RN success.

In the USA, nursing program courses have been studied to identify which courses have the strongest predictive ability for NCLEX-RN success. Theoretical nursing foundations, anatomy and pathophysiology course grades were found to be significant. ${ }^{[1,7]}$ Nursing fundamentals, adult health nursing, mental health nursing, childbearing, and pediatric nursing course performance have contradictory findings with Alexander and Brophy ${ }^{[14]}$ finding significant correlations between those that pass and those that fail the NCLEX-RN, while Uyehara, Magnussen, Itano, and Zhang ${ }^{[8]}$ found no significant difference by course grades. Beeson and Kissling ${ }^{[6]}$ focused on all courses encountered in post-secondary education and found that anatomy, physiology, microbiology, psychology, sociology and lifespan development had a high correlation with NCLEX-RN pass rates if the student achieved a "C" grade or higher. Sayles, Shelton, and Powell[10] focused on the association between NCLEX-RN success and the knowledge of nursing program concepts (course content) rather than courses, and found that knowledge about circulation and oxygenation throughout the lifespan were significantly related to NCLEX-RN success. Collectively, the literature suggests that some nursing courses have significant predictive value for success in writing the NCLEX-RN.

Readiness tests, often administered by universities before a student is allowed to attempt the NCLEX-RN, are intended to demonstrate the level of understanding the student currently possesses about core nursing concepts. While the purpose of readiness tests is to help predict student success on nursing examinations, there have been mixed results of their ability to do so. The National League for Nursing (NLN) comprehensive achievement test appears to be highly sensitive in predicting NCLEX-RN success. Several studies found that NLN comprehensive test scores are statistically significant $(p \leq .001)$ in predicting NCLEX-RN success..$^{[8,14,15]}$ Harding, ${ }^{[16]}$ however, found that the NLN results are significantly associated with NCLEX-RN success, but that this finding did not hold up under logistic regression. Harding' ${ }^{[16]}$ study is the only one located in the literature that suggests NLN results might not predict NCLEX-RN achievement. Similarly, in assessing the Mosby Assess Test (MAT) readiness test, Harding, ${ }^{[16]}$ found that while MAT results appeared to have predictive value, that relationship did not continue under logistic regression. However, many studies have found the MAT to have high predictive value $(p \leq .000) .{ }^{[6-8]}$ The only test that Harding ${ }^{[16]}$ found to have positive predictive value was the Health Education Service Incorporated (HESI) examination. HESI results were found to have a predictive rate of $96.4 \%$ to $98.3 \%$ for the NCLEX-RN; however, this may only be for the first administration of this readiness exam. This is also validated by other HESI studies. Daley, Kirkpatrick, Frazier, Chung, and Moser $^{[7]}$ found the HESI was a significant predictor with greater sensitivity, specificity, test efficiency and negative and positive predictive value than other preparatory examinations. The HESI was also a component of a model that predicted NCLEX-RN success along with nursing GPA and failing grades. ${ }^{[12]}$ Studies examining the association between Nursing Entrance Test (NET) results and NCLEX-RN success also show contradictory evidence. Tipton, Pulliam, Beckworth, Illich, Griffin, and Tibbitt ${ }^{[11]}$ found that a high overall NET score did not significantly predict a pass on the NCLEX-RN. Sayles, Shelton, and Powell ${ }^{[10]}$ analyzed the components of the NET and found significant correlations between NCLEX-RN scores and NET mathematics and reading components along with the NET composite score. Studies examining the relation- 
ship between NCLEX-RN results and the American College Testing (ACT) scores show less variation, however this may be because of the smaller number of studies. Sayles, Shelton, and Powell ${ }^{[11]}$ found ACT scores as significant for NCLEXRN success prediction as did Daley, Kirkpatrick, Frazier, Chung, and Moser. ${ }^{[7]}$ Only McGahee, Gramling, and Reid ${ }^{[1]}$ were found to have assessed the Registered Nursing (RN) assessment test scores and found that they are significant in predicting NCLEX-RN success. Overall, while there is a variety of a readiness assessment test, there is variability across the evidence regarding the association of these tests with NCLEX-RN results.

\subsection{Cognitive factors}

There are a variety of cognitive factors that have been assessed for predictive value in relation to success on the NCLEX-RN. These factors range from test-taking type and critical thinking skills to emotional states. Sayles, Shelton, and Powell ${ }^{[10]}$ assessed different types of test-takers and found a significant predictive value for NCLEX-RN success for visual, writing, and oral learning styles and capabilities in test-taking. However, Tipton, Pulliam, Beckworth, Illich, Griffin and Tibbitt ${ }^{[11]}$ evaluated different test-taking capabilities and found no significant results for predicting success. There is variance regarding the significance of the relationship between critical thinking skills and success on the NCLEX-RN. Romeo ${ }^{[2]}$ investigated critical thinking skills and NCLEX-RN performance and did not find significant relationship. Giddens and Gloeckner, ${ }^{[13]}$ however, found critical thinking skills are highly correlated with NCLEXRN success, especially in truth seeking, open-mindedness, synthesis, and maturity. Arathuzik and Aber ${ }^{[9]}$ also found a positive correlation between critical thinking and NCLEXRN success along with a sense of competency which was evaluated using a study skills self-efficacy instrument. They also found a better NCLEX-RN performance was inversely correlated with high negative emotion as rated by the Internal Block Scale and performance on the NCLEX-RN. ${ }^{[19]}$ This is similar to the findings of Sayles, Shelton, and Powell ${ }^{[11]}$ who documented an inverse correlation with high negative emotion? Results from a study by Tipton, Pulliam, Beckworth, Illich, Griffin, \& Tibbitt ${ }^{[11]}$ studies differ from those of Sayles et al. ${ }^{[10]}$

\subsection{Individual factors}

Individual factors such as gender and ethnicity appear to have little influence on predicting NCLEX-RN success, although there is conflicting evidence from studies with varying methodologies and some with small samples. Measures of family demands, similar to the previous stress component, are often found to be highly inversely correlated and signif-

Published by Sciedu Press icantly related to the success of a student on the NCLEXRN. ${ }^{[9,10]}$ The only other uncontested individual factor found in the literature was speaking English as a first language, which is highly correlated with NCLEX-RN success. ${ }^{[9]}$ Age of the NCLEX-RN writer is both supported and disputed as having a positive correlation with NCLEX-RN success. Daley, Kirkpatrick, Frazier, Chung, \& $\operatorname{Moser}^{[7]}$ found an older age to be a significant factor predictive of NCLEX-RN success. Beeson \& Kissling ${ }^{[6]}$ found that individuals over the age of 35 are more likely to pass the NCLEX-RN, while Haas, Nugent, \& Rule ${ }^{[3]}$ found students below the age of 24 to be more successful. Sayles, Shelton, \& Powell ${ }^{[10]}$ and Giddens \& Gloeckner ${ }^{[13]}$ found age to be an entirely unrelated factor. There is a similar debate as to whether gender is a significant factor for NCLEX-RN success. Three studies found gender to be an unrelated factor ${ }^{[6,10,13]}$ while others have shown male NCLEX-RN writers fail at higher rates compared to those of females. ${ }^{[3,17]}$ These findings could be due to the small sample of men participating in these studies. Small sample sizes may also impact existing studies on ethnicity as a predictive factor. While most studies find ethnicity to be a significant factor, ${ }^{[7,10]}$ some studies found students identified as ethnically Filipino to have lower NCLEX-RN pass rates, ${ }^{[17]}$ while others identify African American students as the lowest NCLEX-RN passing cohort. ${ }^{[3,17]}$ The majority of individual factor studies cite small sample size as a study limitation. In brief, individual factors' ability to predict NCLEX-RN success or failure varies across the literature.

\subsection{Models for success}

Some studies have identified combinations of factors that interact to predict students' NCLEX-RN success or failure. McGahee, Gramling, and Reid (McGahee et al. ${ }^{[1]}$ found that combining the RN assessment test and pathophysiology course grade resulted in the most significant interaction to predict NCLEX-RN success. Simon, McGinniss, and Krauss ${ }^{[5]}$ found course grades for "nursing one", combined with overall nursing program GPA to create an NCLEX-RN performance predictive model. Haas, Nugent and Rule ${ }^{[3]}$ created a different NCLEX-RN performance predictive model that included nursing program GPAs along with SAT scores, age, race, and gender; this model was $70 \%$ successful at identifying those that would pass or fail the NCLEX-RN.

Across the literature, evidence regarding the utility of academic, cognitive, and individual factors as predictors of NCLEX-RN success varies. Interactions complicate the issue more as unrelated factors can become predictive when interacting with predictive factors. This is an issue that begs for untangling. 


\section{DisCUSSION AND IMPLICATIONS}

This systematic review indicates that academic factors are the most researched and that there is strong evidence supporting their utility in NCLEX-RN success predictions. Students' entry to program GPAs, as well as overall program GPAs, are significant predictors of NCLEX-RN success. The evidence also suggests that certain courses have stronger predictive value compared to others. Accordingly, nursing programs may need to pay more attention to entrance requirements and criteria. One way of doing this may be by selecting students with higher per-admission GPAs, ${ }^{[18]}$ with caution noted that different pre-program educational sites may grade students differently. To screen for this potential, the introduction of academic assessments or qualifying tests that distinguish program candidates and stratify them based on academic readiness for the program may be useful. High school guidance workshops can also clarify expectations and promote better career planning. ${ }^{[19]}$ The use of standardized entrance and exit exams, and clinical proficiency tests as graduation requirements have been shown to be useful in predicting readiness and success in NCLEX-RN exams. ${ }^{[20]}$ It may also be useful to monitor students' success across the years of the program, with a view to reviewing and/or modifying program entrance criteria every few years. Throughout the program, students' performance in certain courses such as pathophysiology, anatomy and nursing fundamentals should be closely monitored and evaluated, since several studies have shown these particular courses have predictive value for NCLEXRN success. ${ }^{[21]}$ These evaluations may have implications for the provision of supplemental learning activities and/or peer tutoring programs for students who are not demonstrating high academic achievement in those courses.

Critical thinking skills seem to be correlated with NCLEXRN success. Accordingly, nursing program should strive to teach and reinforce these skills. Inserting targeted learning activities, modifying teaching style towards helping students take ownership of their own learning and practice of these skills may be of utmost importance. Appropriate methods of evaluation of these skills need to be part of every nursing program. $^{[22]}$

Stress and highly negative emotions tend to inversely correlate with NCLEX-RN success. Accordingly, it is important to ensure appropriate and adequate psycho-social supports and counselling are available to students throughout the program. Specific stress management services and sufficient accessibility to mental health and other non-academic support services need to be part of the school environment. ${ }^{[23]}$ Inclusion of students in dialogues to assess their needs and to gather their perspectives after living the nursing program and NCLEX-RN experience could add value as programs evolve over time. ${ }^{[24]}$

\section{RECOMMENDATIONS AND FUTURE STUD- IES}

As NCLEX-RN has entered its first year in the Canadian environment, it is recommended that research studies begin immediately, regionally, provincially and nationally in Canada. Studies of academic, cognitive and individual factors to predict NLCLEX-RN success will be required to determine if existing evidence is generalizable within Canada, and potentially other jurisdictions if or when the NCLEX-RN is more broadly adopted. Cross-sectional and longitudinal data regarding students' perspectives needs to be studied. Studies of pass rates at baseline and at frequent intervals, perhaps in 3, 5 and 10 years will be helpful to assess student and program factors related to NCLEX-RN success. Comparative analysis of performance on the NCLEX-RN with overall undergraduate program performance and specific course performance needs to be conducted. Canadian nursing schools need to collaborate to gather meaningful data and to discuss measures that can promote success. Comparative international analyses would be useful to determine if jurisdictional factors are at play.

\section{Conclusions}

There is much work to be done to advance the identification of factors predictive of NCLEX-RN success. With the NCLEX-RN just entering the Canadian arena, not only does examination of factors in this jurisdiction need to begin, but also evaluating the outcomes of this exam needs to be performed annually. Subsequently, updating curricula, teaching styles, and delivery methods would be of utmost importance to support students' success.

\section{ACKNOWLEDGEMENTS}

We thank Steven R. Conlon for his technical assistance with the line art.

\section{CONFLICTS OF INTEREST DISCLOSURE}

The authors declare that they have no competing interests.

\section{REFERENCES}

[1] McGahee TW, Gramling L, Reid TF. NCLEX-RN@ success: are there predictors. Southern Online Journal of Nursing Research. 2010;
10(4): 208-221.

[2] Romeo EM. The Predictive Ability of Critical Thinking, Nursing G PA, and SAT Scores on First-Time NCLEX-RN Perfor- 
mance. Nursing Education Perspectives. 2013; 34(4): 248-253. http://dx.doi.org/10.5480/1536-5026-34.4.248

[3] Haas R, Nugent K, Rule R. The use of discriminant function analysis to predict student success on the NCLEX-RN. Journal of Nursing Education. 2004; 43(10): 440-446. PMid:17152303

[4] Bosch PC, Doshier SA, Gess-Newsome J. Bilingual Nurse Education Program: Applicant Characteristics that Predict Success. Nursing Education Perspectives. 2012; 33(2): 90-95. http://dx .doi.org $/ 10.5480 / 1536-5026-33.2 .90$

[5] Simon EB, McGinniss SP, Krauss BJ. Predictor Variables for NCLEX-RN Readiness Exam Performance. Nursing Education Perspectives. 2013; 34(1): 18-24. http://dx.doi.org/10.5480/1 536-5026-34.1.18

[6] Beeson S, Kissling G. Predicting success for baccalaureate graduates on the NCLEX-RN. Journal of Professional Nursing. 2001; 17(3): 121-127. PMid:11391557 http://dx.doi.org/10.1053 /jpnu. 2001.23382

[7] Daley L, Kirkpatrick B, Frazier S, et al. Predictors of NCLEX-RN success in a baccalaureate nursing program as a foundation for remediation. Journal of Nursing Education. 2003; 42(9): 390-398. PMid:13677554

[8] Uyehara J, Magnussen L, Itano J, et al. Facilitating program and NCLEX-RN success in a generic BSN program. Nursing Forum. 2007; 42(1): 31-38. PMid:17257393 http://dx.doi.org/10.11 $11 / j .1744-6198.2007 .00063 . x$

[9] Arathuzik D, Aber C. Factors associated with National Council Licensure Examination - registered nurse success. Journal of Professional Nursing. 1998; 14(2): 119-126. http://dx.doi.org/10.1016/S 8755-7223(98) 80040-9

[10] Sayles S, Shelton D, Powell H. Predictors of success in nursing education. ABNF Journal. 2003; 14(6): 116-120. PMid:14969016

[11] Tipton P, Pulliam M, Beckworth C, et al. Predictors of associate degree nursing students' success students. Southern Online Journal of Nursing Research. 2008; 8(1).

[12] Lavandera R, Whalen DM, Perkel LK, et al. Value-Added of HESI Exam as a Predictor of Timely First-Time RN Licensure. International Journal of Nursing Education Scholarship. 2011; 8(1): 1-12. http://dx.doi.org/10.2202/1548-923X. 2152

[13] Giddens J, Gloeckner G. The relationship of critical thinking to performance on the NCLEX-RN. Journal of Nursing Education. 2005; 44(2): 85-89. PMid:15719716
[14] Alexander J, Brophy G. A five-year study of graduates' performance on NCLEX-RN. Journal of Nursing Education. 1997; 36(9): 443-445. PMid:9362029

[15] Barkley TJ, Rhodes R, Dufour C. Licensure examination. Predictors of success on the NCLEX-RN among baccalaureate nursing students. Nursing \& Health Care Perspectives. 1998; 19(3): 132-137. PMid:10426110

[16] Harding M. Predictability Associated with Exit Examinations: A Literature Review. Journal of Nursing Education. 2010; 49(9): 493-497. PMid:20669877 http://dx.doi.org/10.3928/01484834-201 00730-01

[17] Seago J, Spetz J. California's minority majority and the white face of nursing. Journal of Nursing Education. 2005; 44(12): 555-562. PMid: 16402738

[18] Briscoe VJ1, Anema MG. The relationship of academic variables as predictors of success on the National Council Licensure Examination for Registered Nurses (NCLEX-RN) in a selected associate degree program. Association of Black Nursing Faculty Journal. 1999; 10(4): 80-83.

[19] Campbell-Heider N1, Sackett K, Whistler MP. Connecting with guidance counselors to enhance recruitment into nursing of minority teens. Journal of Professional Nursing. 2008; 24(6): 37884. PMid:19022212 http://dx.doi.org/10.1016/j.profnur s. 2008.10.009

[20] Crow CS1, Handley M, Morrison RS, et al. Requirements and interventions used by BSN programs to promote and predict NCLEXRN success: a national study. Journal of Professinal Nursing. 2004; 20(3): 174-86. http://dx.doi.org/10.1016/j.profnurs. 20 04.04 .004

[21] Bryer J. Peer tutoring program for academic success of returning nursing students. Journal of New York State Nurses Association. 2012; 43(1): 20-22. PMid:23189512

[22] Azizi-Fini, Hajibagheri, Adib-Hajbaghery. Critical thinking skills in nursing students: a comparison between freshmen and senior students. Nursing and Midwifery Studies. 2015; 4(1): e25721. PMid:25830160

[23] Chernomas WM, Shapiro C. Stress, depression, and anxiety among undergraduate nursing students. International Journal of Nursing Education and Scholarship. 2013. http://dx.doi .org/10.1515/i jnes-2012-0032

[24] Eddy LL1, Epeneter BJ. The NCLEX-RN experience: qualitative interviews with graduates of a baccalaureate nursing program. Journal of Nursing Education. 2002; 41(6): 273-278. PMid:12096776 